\title{
Shared Spaces in Cities of Poland
}

\section{Andrzej Zalewski}

UTP University of Science and Technology, Bydgoszcz (Poland)

\section{Abstract}

The aim of paper is a presentation an idea of shared space in the cities and results of implementation of this solution in the cities of Poland. The methodology of elaboration consisted of carrying out a review of the literature, comparing existing solutions and formulating conclusions regarding implementation. This trend, which has appeared over the past 50 years as a counterbalance to the pedestrianization of public spaces, is at the beginning of the 21st century experiencing its second youth and is being implemented in many areas in intensive urban development, especially in urban centers and areas of historic character. Shared space solutions are an integral way of shaping functions and forms of revitalized public spaces. These solutions contributes to improving the quality of public space and traffic safety, revitalizing social life, improving and reducing the environmental nuisance caused by traffic and finally created liveable

Corresponding Author:

Andrzej Zalewski

andrzej.zalewski2205@gmail .com

Received: 26 November 2019 Accepted: 13 May 2020

Published: 2 June 2020

Publishing services provided by Knowledge E

(c) Andrzej Zalewski. This article is distributed under the terms of the Creative Commons

Attribution License, which permits unrestricted use and redistribution provided that the original author and source are credited.

Selection and Peer-review under the responsibility of the ICEUBI2019 Conference Committee.
G OPEN ACCESS city. Analyzes effectuated indicate, that in central areas of cities in Poland whose spatial arrangement is legally protected, the forms of shared spaces solutions are strongly influenced by strong conservation restrictions in these areas. This means the need to respect existing historical conditions in shaping public spaces, as well as limited transformation possibilities. The Polish solutions of shared spaces presented in this paper of in their forms and quality do not differ from the standard functional solutions abroad. Solutions implemented in the Polish conditions, however, are more modest in terms of materials and implemented in a smaller number than is the case in Western European countries.

Keywords: Shared spaces, Traffic calming, Cities of Poland, Creation of public space

\section{Introduction}

The idea of traffic calming is developing in towns and agglomerations is for almost half a XX century and which posed many of implementations in historical areas. The traffic calming is „the settlement and adaptation to his basic functions the transportation way of service of area and the usable character, cultural and ecological" [1].

The calming of traffic according to authors of Integrated Programme of Improvement of Road Traffic Safety in Poland the GAMBIT (1996) [2] can define as „the solution about organizational, building and legal character, reducing the difficulty of car traffic by sews on him limitations and the change of transportation service of chosen areas. The means 
of traffic calming can have the character of planning and structural solutions, detailed solutions of elements of roads and the organization of traffic".

Traffic calming solutions are very different nature. Beside typical solutions woonerf, through the streets - the tempo 30 , to the streets leading to the speed limit to $50 \mathrm{kph}-$ environmentally friendly. Solutions of this type very well placed in the city centers and historic areas where sharing space with pedestrians and vehicles is conditioned by the development of natural and historical heritage.

Solutions of the shared space as a form of traffic calming idea implemented in the public space for many years. These are the spaces created in the historical development, or completed in the last half century as a practical exemplification of the ideas contained in the concepts C. Buchanan "Transportation service of Norwich centre) [3], SCAFT „traffic replanning” [4] and ideas Woonerf [5]. In 1970, Dutch city planners J. Gisges and H.G. Vahl in the Delft in the Netherlands completed a the first solution according to the concept Woonerf, which is considered the prototype of the "modern traffic calming" [6].

\section{Aim of Paper}

The aim of paper is a presentation an idea of shared space in the cities and results of implementation of this solution in the selected cities of Poland in the base of basics of traffic calming concepts.

\section{The Methodology of Analysis}

The methodology of elaboration consisted of carrying out a review of the literature, comparing existing solutions and implementation and development of photographic documentation and to compare existing solutions as well as formulating conclusions regarding implementation. In choosing examples of shared space solutions in Poland, the author was guided by showing their representativeness among Polish cities and at the same time a diverse form of implementation: from the street, where a road and pavements were separated on a common surface, through a classic "Woonerf "to the street (Lodz - 8 August and Traugutta street), where preserved natural form without introducing additional street furniture (Warsaw - Payment Street, 4 Streets in the centers in medium or small size cities, which would implement qualities of space. The examples of solutions shared space show that this type of solutions can operate in buildings with various functions, including city centers (Lodz-Piotrkowska, 8 August and Traugutta Streets, Gorzow WIkp. - Sikorskiego Street) and residential districts (Payment 
Street in Warsaw). Sections of historical itinerary in the inner area - Warsaw - Cracow Suburb and New World Streets. Selected examples are the author's approach to the exemplification of shared spaces in Polish conditions

\section{Results and Discussions}

\subsection{Development of shared space as a part of traffic calming idea}

Dutch Ministry of Transport describes "Woonerf" as "a detail designed and decorated street in the area of housing, which is a function of housing is leading, and vehicular traffic is subordinate to this function. The main objective of Woonerf was to improve the living conditions of the environment, including in particular in the central districts of large and big cities. It is these areas most affected by transportation nuisance [5].

An important novelty in the concept Woonerf were [7]:

- special traffic rules, which introduced traffic of the joint surface of pedestrians and vehicles,

- the introduction of equality and traffic reduction of speed close to pedestrian traffic,

- a ban on mutual hindering the movement,

- permitting playground in the entire cross-section of the road, with extreme caution on the part of drivers,

- principle of traffic priority from the right,

- permitting parking only in certain areas and the introduction of a special vertical signage.

The concept Woonerf, which liquidated the division of public space on the part of the street for pedestrians and vehicles, despite initial rapid development has not worked to the end.

Disadvantages, which turned out to be:

- very high costs of the projects and their operation,

- difficulties in access for heavy traffic, because of the geometry and realized "furnishings" streets and parked cars,

- migration of accidents and increase the risk of accidents and children living in areas Woonerf on other streets outside the "island of safety", 
- smaller number of parking spaces possible to extract than traditional solutions,

- difficulty reconciling the development of green or recognition of the internal by outsiders.

- the lack of adaptation of space for the outward and visually impaired and for the deaf people.

This concept is considered the first generation of the modern concept of traffic calming in form functional - technical as well as in the context of the size of solutions - street traffic calming. The concept quickly gained popularity. But negative aspects Woonerf meant that over the years planners departed from the idea (extremely besides new realizations residential areas) in favour of the concept of a lower speed, and similar effects is a "zone tempo 30" - which is the second generation of traffic calming in terms of form functionality - technical.

It retains segregation traffic of different categories of users of public space with a speed limit traffic to $30 \mathrm{kph}$ with the possibility of implementation small architecture space arrangers (bumps, narrowings, chicans deviations, or repavement).

In 1991, H. Monderman [8] said that creating a space a higher degree of uncertainty behaviour of other road users (growth risk), entering a situation in which there is no certainty as to who has priority, makes all participants of traffic will decrease the tendency to take risky actions. Implementation of this approach were to be just "shared spaces", which functional solutions - space based on the assumption provide space eye contact driver - pedestrian, forcing calm driving at low speed. Since then, a solution that the nature of traffic calming to the revised division of the street between the forms of movement while the speed limit car traffic is defined as the shared spaces.

They are characterized by a large diversity of organizational-technical forms, from the pedestrian areas, by type solutions of city courtyard the speed limit between 20-50 $\mathrm{kph}$. A common feature of these solutions is alleviated the differences in height in crosssection and the creation of a common shared space for all traffic participants. Driving track cars are shaped in the manner typical for traffic calming, often with a characteristic chicans deviations. Development of cross-street section must be adopted to the traffic speed limit and to the place where it is implemented. 


\subsection{Shared spaces in urban public space}

In the development by author of model of Gunnarson of urban public transportation space solutions of shared space are situated majority in traffic calming zones including "pure" traffic calming zone (tempo 30-40), integrated pedestrian and traffic zone (woonerf) and partially integrated traffic calming and a through traffic zone (40-50 kph), as well as in special situation pedestrian zones. Relations between shared spaces and mentioned traffic calming zones are presented in Figure 1. This means that the forms of shared spaces solutions can be very diverse and should be adapted to the conditions and traffic safety determined by the permissible speed of vehicles as well as pedestrian and bicycle traffic.

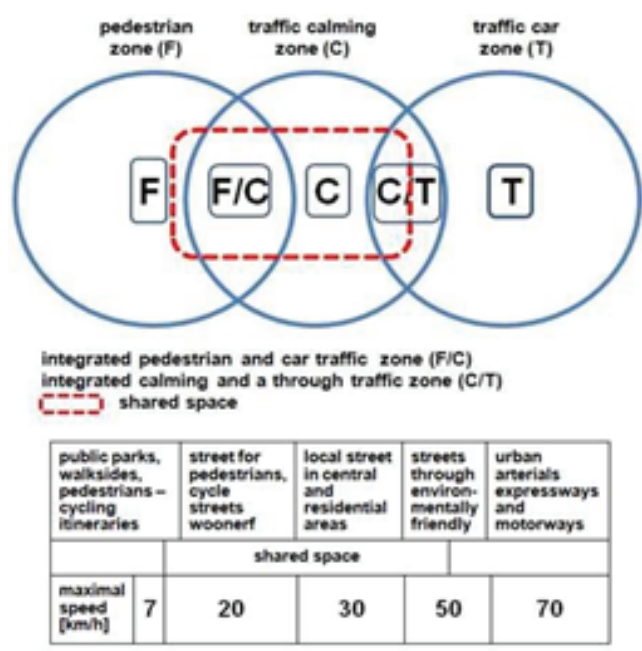

Figure 1: Shared space solutions in urban public tranportation space by O. Gunnarsson with supplement of A. Zalewski

\subsection{Examples of shared spaces in the Polish Cities}

Shared space in a part of representative itinerary of Royal Route in Warsaw ( $>1700,000$ inhabitants) was created in the Cracow Suburb and New World Streets (Figures 23). These streets are examples of the street itinerary, where the traditional distinction between the sidewalks and the roadway while reducing speeding traffic is preserved.

The revalorization of these streets was performed generally by the implementation of new stone pavement and narrow cross-section. there are not chicans so characteristic for traffic calming solutions on this street, because it is a very important route connecting the representative public offices in Poland (Palace of the President, the Parliament and the Government and several ministries). Therefore, traffic should take place without obstacles. 


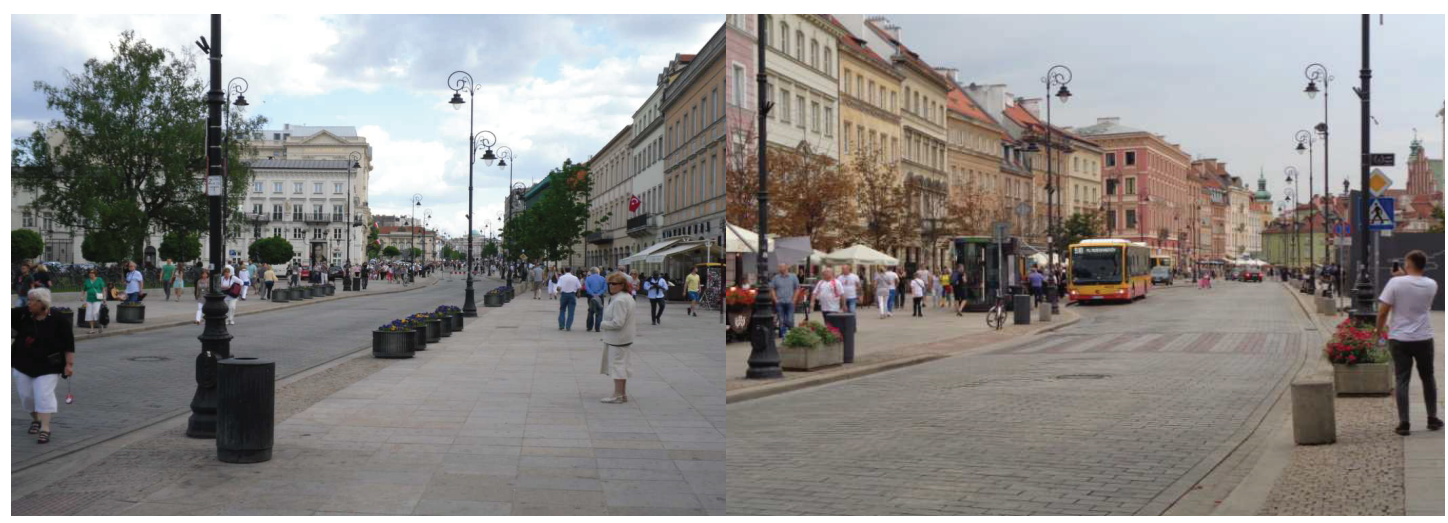

Figure 2: Warsaw - Cracow Suburb Street - part of Royal Road - access for buses of transport public, taxi, cars with permissions, cyclists and pedestrians (tempo 40); Photos by A. Zalewski 2019

After rebuilding the streets have gained an attractive appearance and are a favourite place for walks of residents of Warsaw.

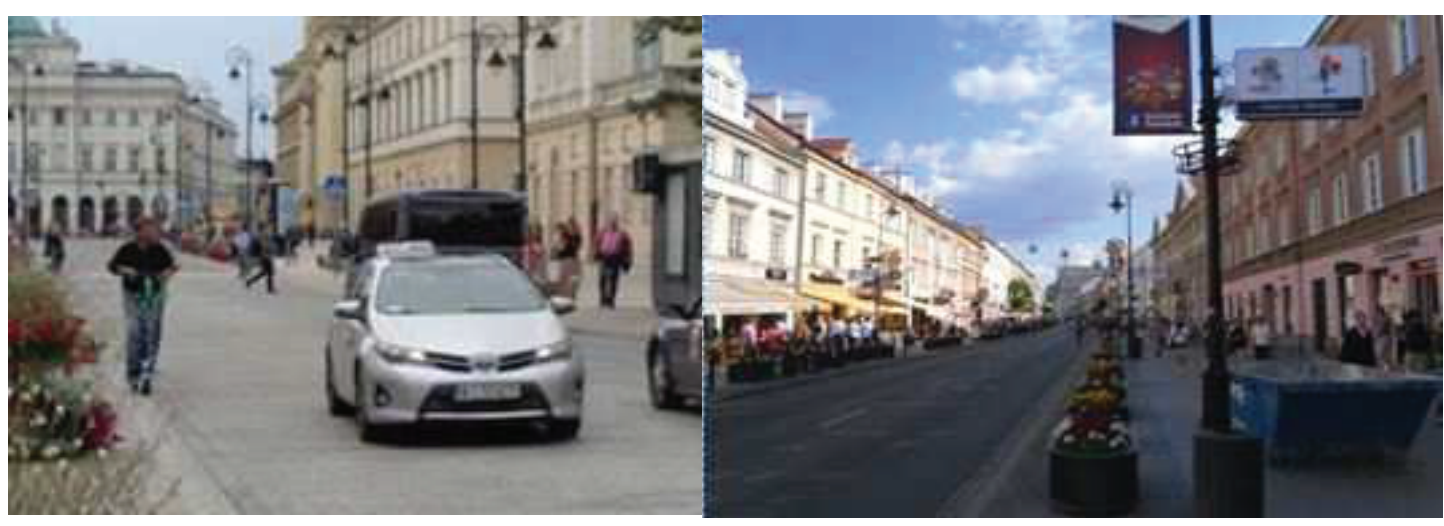

Figure 3: Warsaw - Cracow Suburb Street (left) and New World Streets (right) - sections of Royal Road access for buses of transport public, taxi, cars with permissions, cyclists and pedestrians (tempo 40); Photos by A. Zalewski 2012 and 2019

The Piotrkowska Street in the city of Lodz $(650,000$ inhabitants) is a representative pedestrian street, as well as a main axe of creation of public shared space of the city downtown. Street since many years is available only for pedestrians, bicycles, traffic inhabitants and supplies (Figures 4 - 6).

\section{Transformation of local streets in Woonerf solutions in the centre of the City Lodz}

-- During the last six years in downtown Lodz a few of the local streets were transformed into shared spaces in convention of woonerf. Their purpose was primarily to substantial reduction of car traffic and giving the public the new values. Solution of Woonerf is functioning after the reconstruction on the 6 August Street and R. Traugutta Street, where in the stone surface made uniform over the entire cross-section and street "been furnished" (Figures 7 - 9).

These solutions: 


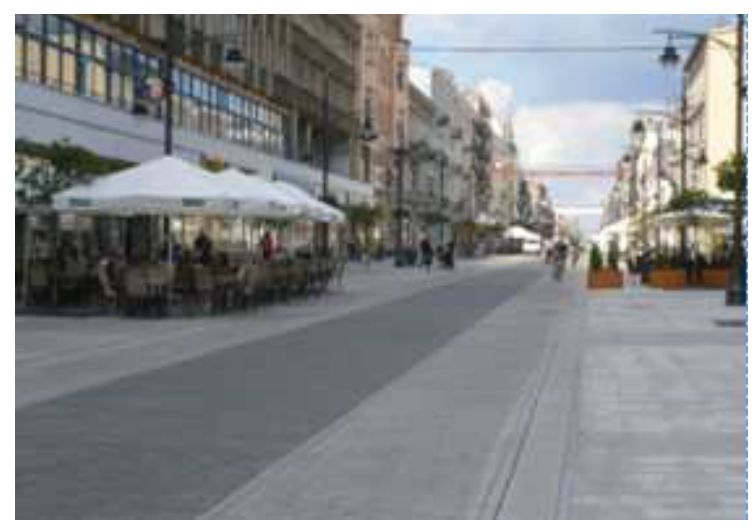

Figure 4: Lodz - Piotrkowska Street- shared space - access for pedestrian, cyclists and local traffic car (left) and summer coffee garden (right); Photos by A. Zalewski 2013

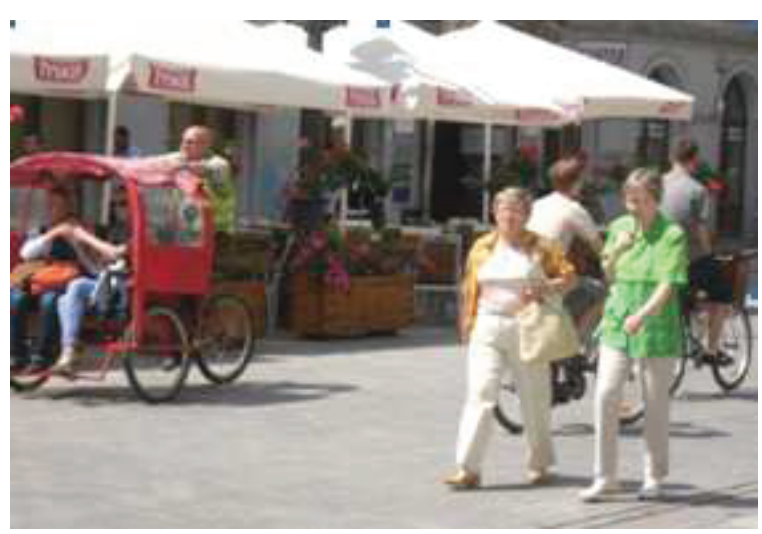

Figure 5: Lodz - Rickshaws on the northern stretch of Piotrkowska Street - shared space; Photos by A. Zalewski 2013

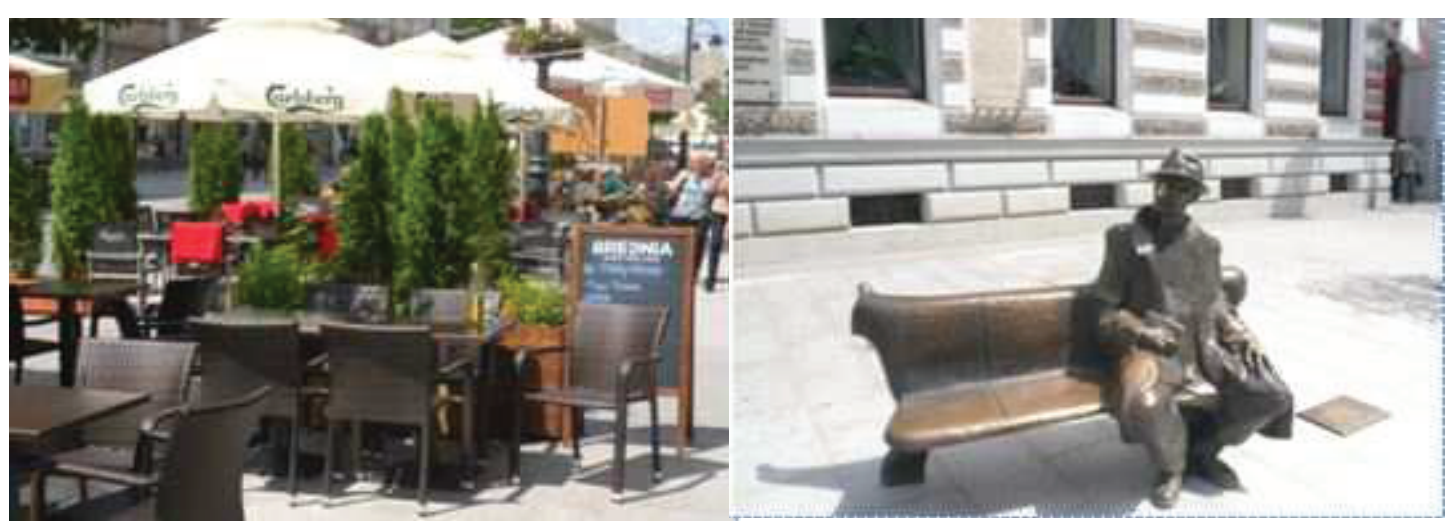

Figure 6: Lodz The Gallery of Greater Lodzians in public space of Piotrkowska Street - banc of J. Tuwim; Photos by A. Zalewski 2013

- have met with very good acceptance among residents and led to a significant increase in revenues restaurant owners,

- improved environmental and landscape conditions,

- are attractive places for meetings and walks of inhabitants and tourists as well as to organize public urban events. 
Given the success of the measures taken, the municipal authorities have taken creation of new reconstruction of streets as Woonerf - shared space.

In spectacular success of shared space in the Lodz centre, local authorities transformed a next few local streets in residential area in this type as part of the municipal revitalization program.

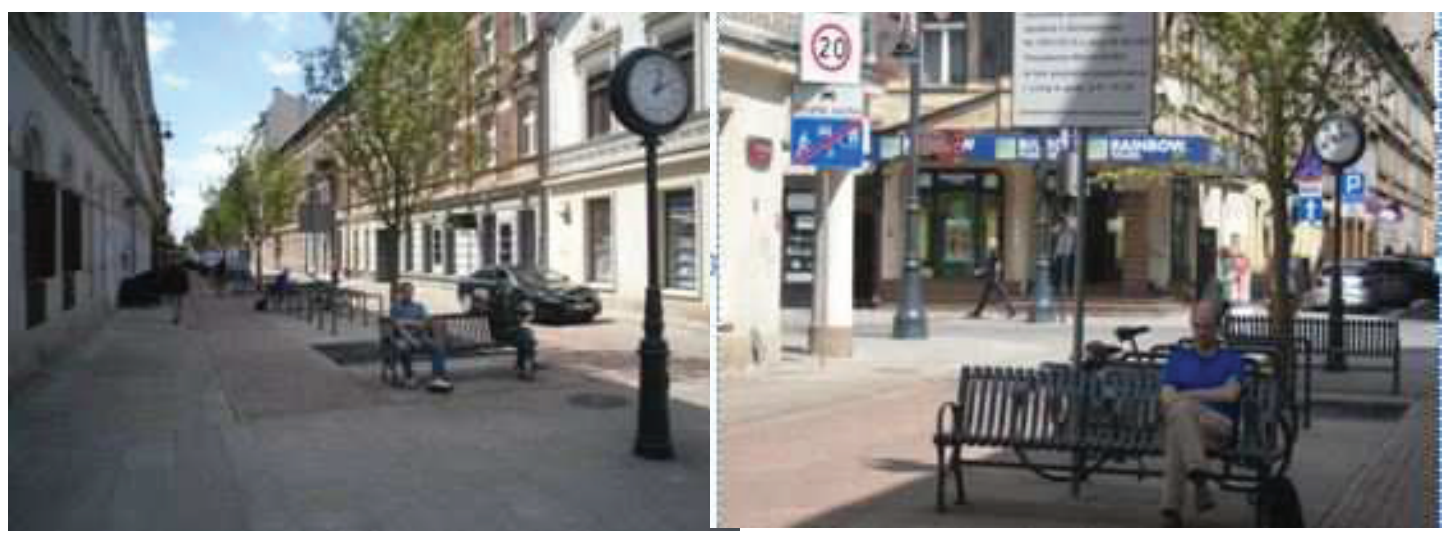

Figure 7: Lodz - 6 August Street - shared space w downtown in convention of „woonerf”; Photos by A Zalewski 2014

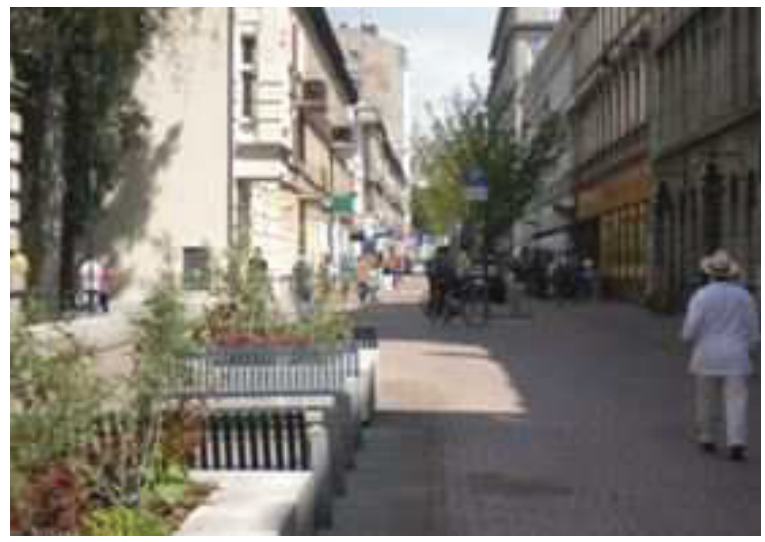

Figure 8: Lodz - 6 August Street - shared space w downtown in convention of „woonerf”; Photos by A. Zalewski 2014

Warsaw-Bielany - An example of a "natural" solutions shared space in the individual residential area is a Payment Street in residential zone Workers' Prey in Bielany District in Warsaw (150,000 inhabitants). The street is the function of access road. In existing form was built in the thirties of the XX century. In the last few years has been revitalized, which metwarmly welcomes residents (figures 10).

The concept of a traffic calming zone in the center of Gorzow Wielkopolski (125,000 inhabitants) presented in Figure 11 is an example of shared space solutions can be an integral element of transport service shaping solutions using the idea of traffic calming and public spaces in the city center. 


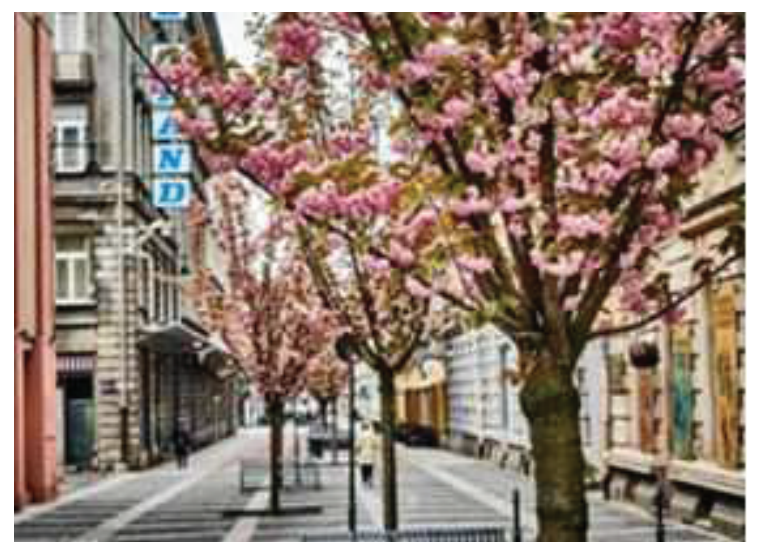

Figure 9: R. Traugutt Street in the flowering cherry trees Kanzan - woonerf section between Piotrkowska St. and Sienkiewicza St. (May 2017); source: [9]

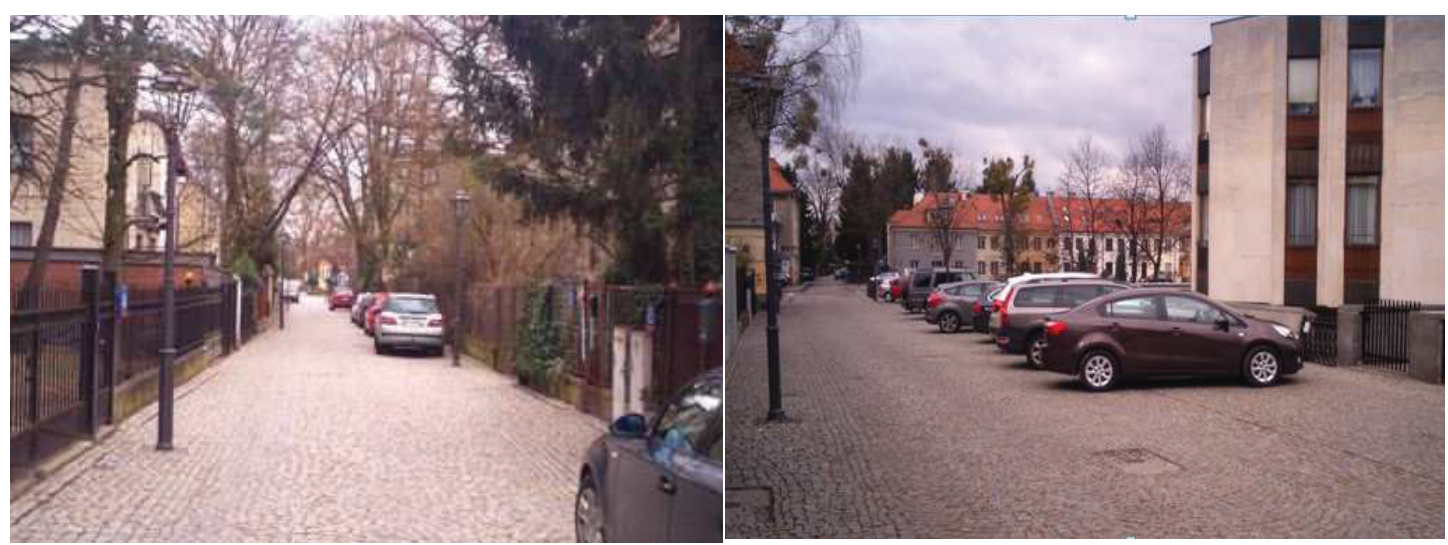

Figure 10: Warszawa -Payment Street in Warsaw - example of shared spaced in residential area (tempo 30); Photos by A. Zalewski 2018;

Shared space in the center of Gorzow Wielkopolski. covers a large part of traffic calming zones. A project of Gen. Sikorski Street as a shared space on the section between the intersections with Chrobry Street and with Herbert Street presented in Figures 12 is an example of how you can integrate a tram line, bicycle and pedestrian traffic as well as vehicle access traffic to the property while increasing the aesthetic value of public space

By using appropriate construction measures, including primarily the floor design, as the "third dimension" of space can obtain very beneficial effects. The above example also shows that in order to introduce a calming of traffic in a section of a street in the form of shared space, one should take into account the need to introduce changes in the transport service of an area much larger than a street transformed into a shared space.

The solutions in: Kutno, Swiebodzin Wielkopolski, Biala Podlaska and Jaworzno show typical implementations of shared space in medium and smaller cities (less than 70,000 or 20,000 inhabitants) in different part of Poland, whose main objective was to 


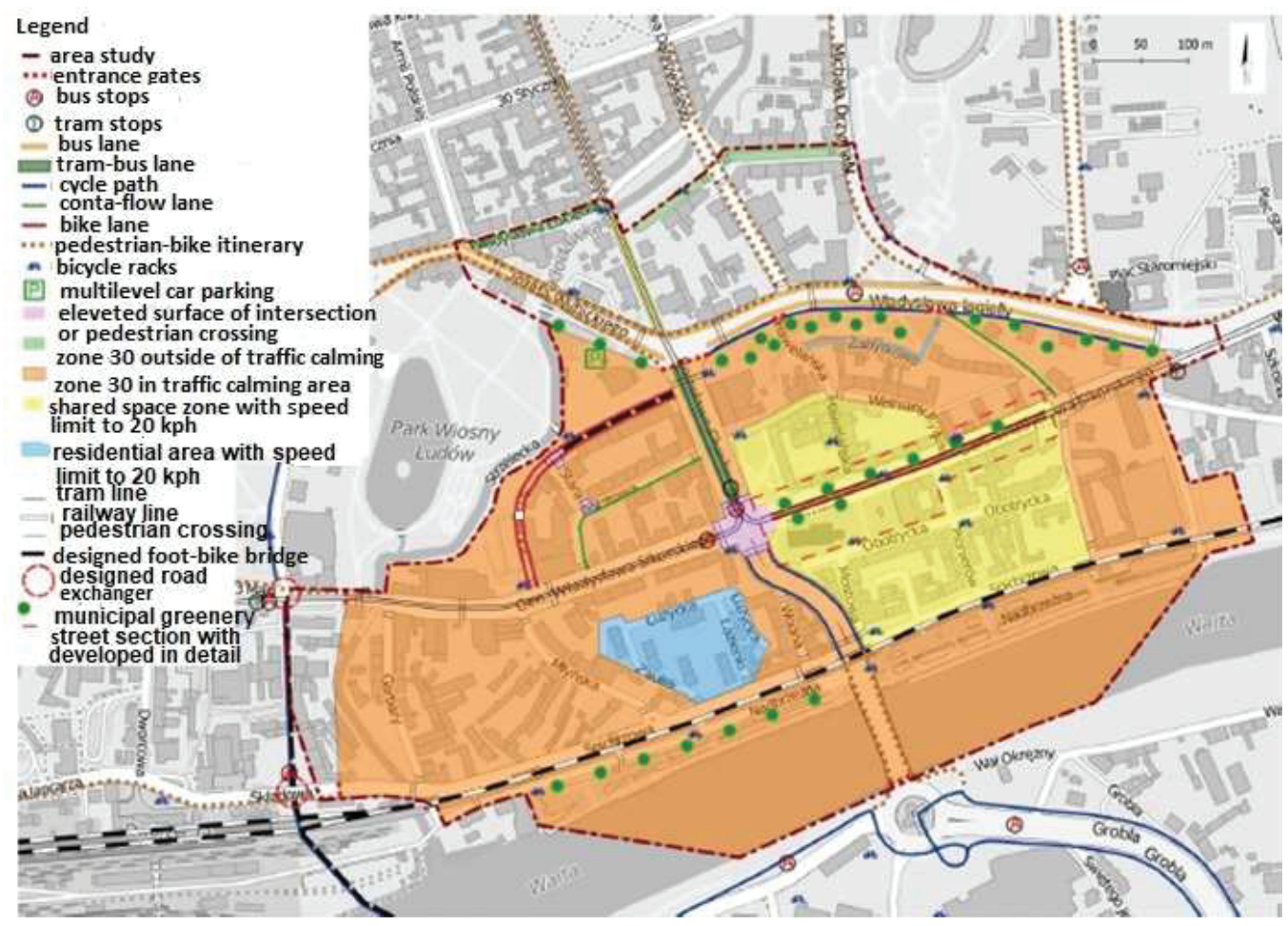

Figure 11: Gorzow WIkp. Concept of traffic calming zone in the Centre with shared space in Main street in this area [11]

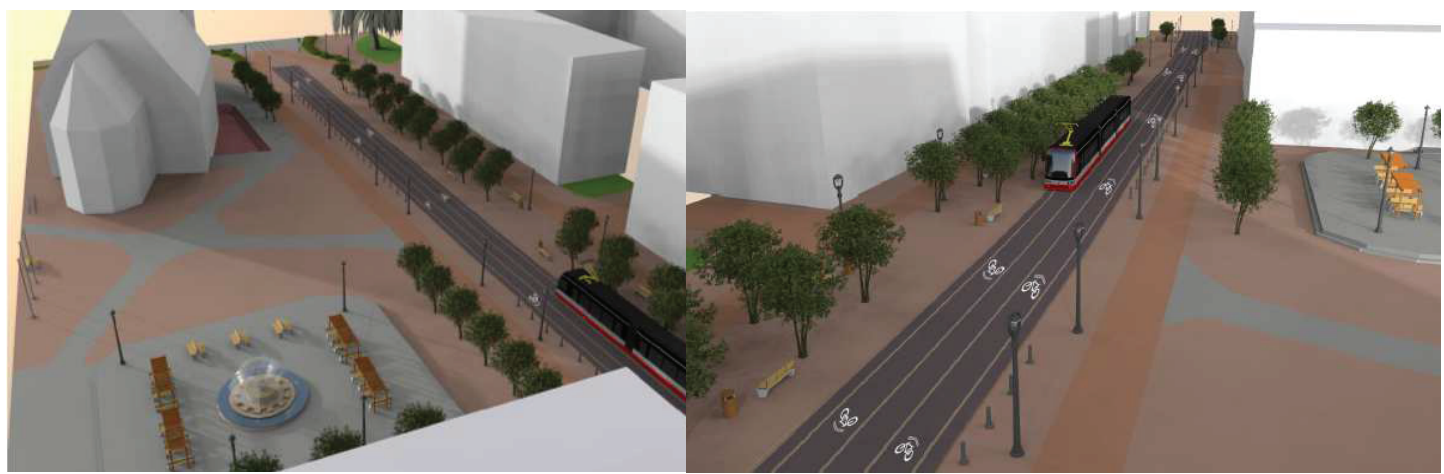

Figure 12: Gorzow Wlkp. Centre - Project of Sikorski Street as shared space between intersections of Chrobry and Herbert Streets - cohabitation of pedestrians, cyclists and trams in common surface; Photos by M.Cieslik 2015 [11];

improve the quality of public spaces of these areas and to create a friendly space for pedestrian traffic, with access for bicycles, traffic inhabitants and supply. All selected solutions are situated in the centers (Figures 13-16).

Transformations of public spaces as shared space was executed during last ten years. Their implementations resulted from the need to improve the quality of public spaces and creates representative streets in the centers of their cities. Before 2000, public spaces in these cities were significantly neglected. The improvement of the wealth of cities and the possibility of obtaining funding from European funds for revitalization has led to their implementation and current appearance. In these cities very they well 


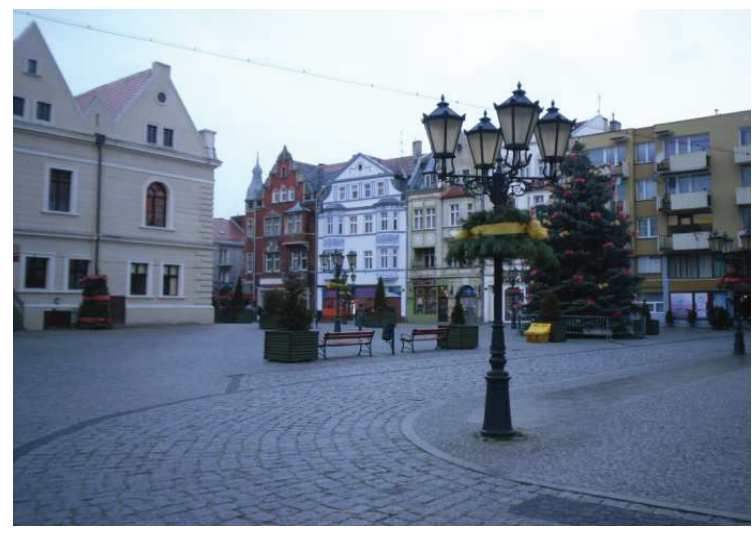

Figure 13: Swiebodzin WIkp. - City Market - shared space area accessible for pedestrian, cyclists and local traffic car; Photo by A. Zalewski 2014

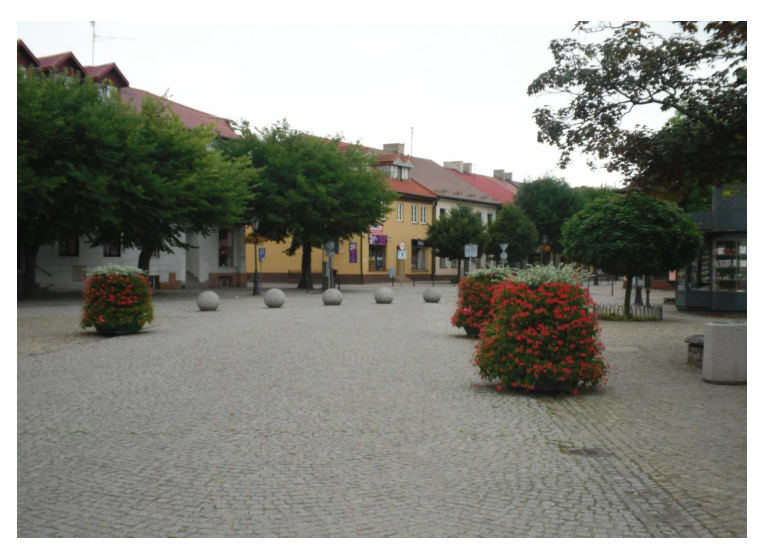

Figure 14: Kutno - Royal Street - shared space area accessible for pedestrian, cyclists and local traffic car; Photo by A. Zalewski 2014

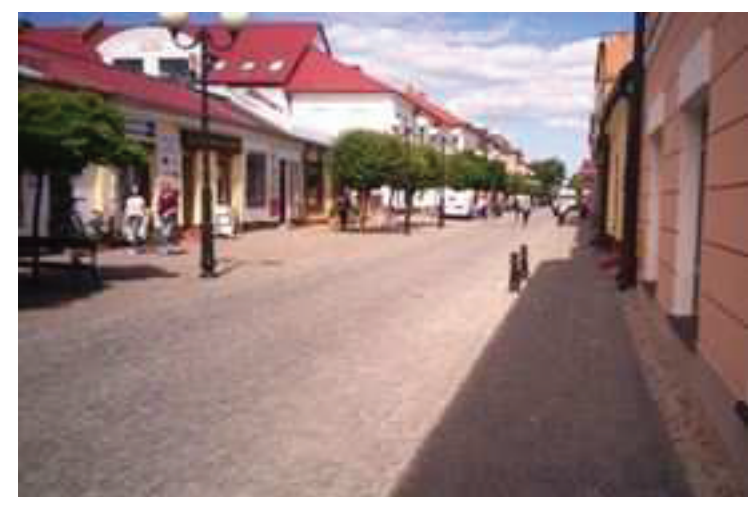

Figure 15: Biala Podlaska - shared space area in the center of city; Photo by A. Zalewski 2014

fulfill their functions and are very attractive for residents and tourists presently. They are showcases of the cities either. 


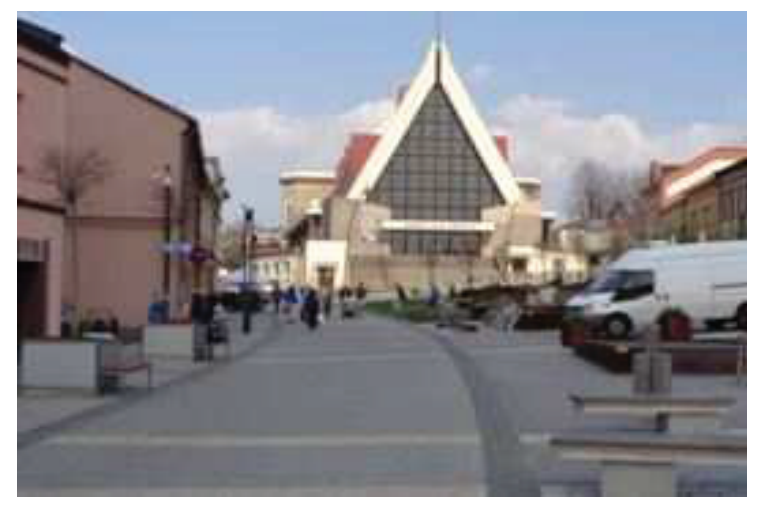

Figure 16: Jaworzno - City Market - shared space area; Photo by A. Zalewski 2014

\section{Conclusions}

1. Solutions of shared space are conception of creation of public spaces in cities, which in the twenty-first century should be attractive and safe for users, and the same time should be available for the various means of transport, so that they are living spaces.

2. Solutions of traffic calming in all forms, including as a shared space are an important element of the activities in terms of policy and sustainable transport system, because they:

- affect into the decrease in intensity of car traffic,

- improve security,

- promote the increased use of bicycles, public transport and pedestrian traffic,

- improve the condition of the natural environment and conditions of residence, and the aesthetics of the urban landscape.

3. Shared space solutions are characterized by a large diversity of organizational forms - technical, from the pedestrian areas, by type solutions courtyard city, the rate "tempo" $20-50 \mathrm{kph}$. A common feature of these solutions is shared by the cross-sectional area street bridge the difference in height between the level of track and pedestrian routes, and the surface dedicated to the road. Driving track cars are shaped in the manner typical for traffic calming, often with a characteristic chicans deviations. Development of cross-street section must be adopted to the traffic speed limit and to the place where it is implemented.

4. The number of users shared space is closely linked to the wide diversity of functional - technical - organizational these solutions. Depending on the form of technical access car traffic may be from 100 vph to approx. 2000 vph [12], which 
means that during the day the street cross-section may even pass under specific conditions the organization of the transportation vehicle even several thousands per day.

5. Shared space solutions that have been implemented and are presented in the media relate mainly to the individual sections of streets. Context of urban development of introduced transformation is rarely discussed. Without taking into account its not possible to assess the reasonableness of solutions.

6. The shared spaces make generally very favourable impression on users in terms of aesthetics and functionality. Significantly improve living conditions and aesthetics of the landscape of the street or square. They are a kind of urban living providing opportunities for the development of the activity and urban life. They encourage residents "to the streets" and to enjoy all the benefits of public space. Development section of the floor (in its form, material), greenery, landscaping elements and lighting (including night illumination) are shaped, usually with very great care.

7. The implementation of the transformation of the streets in the solution space shared involve a change of function using ground floors of buildings. These are usually shopping centers, restaurants, bars that encourage tourists and residents to visit the premises and shops of the reconstructed street.

- The factor determining the formation of traffic calming zones, especially the shared space is a widely understood human aspect. Great importance in the process of shaping and implementing zones and routes traffic calming is the level of awareness and openness to new ideas all participants in the process of design - of execution, that is, designers, contractors, decision makers and end users - the residents. Without wishing to do anything, do not do anything. Factor awareness is particularly important in the Polish conditions, where some professionals responsible for road transport and urban planning in cities and policy makers are not yet convinced about the need for traffic calming.

- In Polish conditions, in central areas of cities whose spatial arrangement is legally protected, the forms of shared spaces solutions are strongly influenced by strong conservation restrictions in these areas. This means the need to respect existing historical conditions in the field of shaping public spaces, as well as limited transformation possibilities.

- The Polish solutions of shared spaces presented in this paper in their forms and quality do not differ from the standard functional solutions abroad. Solutions implemented in the Polish conditions, however, are more modest in 
terms of materials and implemented in a smaller number than is the case in Western European countries.

- For the more numerous implementations, it is necessary to update the legislation, so that the regulations are clear and encourage designers and managers of public spaces to their implementation.

\section{References}

[1] K. Bieda, A. Rudnicki, T. Kopta, A. Zalewski and others, Creation of pedestrian and cycling zones, MR.I.6. - VI/A/3, manuscipt unpublished in Polish, Cracow University of Technology, IUPP, Cracow, Poland, 1984.

[2] GAMBIT - Integrated Program of Improvement of Road Traffic Safety in Poland, Final Report 1994-1996, Ministry of Transport and Maritime Economy, National Road Safety Council, Warsaw, 1996.

[3] C. Buchanan. Traffic in the Towns, Crown Edit, London, Great Britain, 1963.

[4] Gunnarsson O. Urban Traffic Network Design - A Spatial Approach, VTI/BAST International Conference, Göteborg, Sweden, 1990.

[5] J. Kołodziej and T. Siemek, Woonerf and zone of traffic calming - New Concept of designing of transportation in inhabitants area (legal and normative regulations and conditioning of modernization of street interiors (in Polish), p.1, Polish Society of Towns Planers, Warsaw, Poland 1983.

[6] H.G. Vahl and J. Giskes, Urbanisme et trafic de la guerre à la paix, CETUR, Bagneux, France, 1988.

[7] A. Zalewski, Traffic Calming as a Urban Planning Question (in Polish), Publishing of Lodz University of Technology, Science Proceedings no 1104, Science Hearings 414 , Lodz, Poland, 2011.

[8] Efect_of_Peltzman. Wikipedia: Wikipedia: https://pl.wikipedia.org/wiki/ Efekt_Peltzman/ (02/04/2015).

[9] Pierwszy sezon ogrodkowy na Traugutta w Łodzi. http://lodz.naszemiasto.pl/artykul/ pierwszy-sezon-ogrodkowy-na-traugutta-w-lodzi-zdjecia, 3708064,gal,t,id,tm.html (06/05/2017)

[10] Woonerf na Traugutta $w$ Łodzi oficjalnie otwarty. http://lodz.naszemiasto. $\mathrm{pl} /$ artykul/zdjecia/woonerf-na-traugutta-w-lodzi-oficjalnie-otwarty-zdjecia, 3570991, artgal, 17957601, t,id,tm, zid.html ( 06/05/2017).

[11] M. Cieslik, Conditions and possibilities of shaping a calm traffic zone in the center of Gorzow Wielkopolski, Master thesis, promoter A. Zalewski, manuscipt unpublished 
in Polish, Warsaw University of Technology, Faculty of Geodesy, Warsaw, Poland, 2015.

[12] H. Mazur, D. Lauenstein and others, Erfahrungen mit Tempo 30, Umwelt Bundes Amt, Walter Heine Hannover, Germany, 1996. 